\title{
Fluidity in craft and authenticity
}

Increasingly, tangible interaction design is orienting itself towards craft as something distinct from design. There are efforts to translate, or re-produce, the materiality of spaces in other media, calls for a coherent approach to experience and evaluation, and NSF funding aimed at making the concepts and needs of HCI accessible to graphical and traditional crafts communities. In addition, researchers from Indiana University are teasing out a method for designing tangibles starting with metaphors from nature. They speak of this as a designerly approach, emphasising an 'old' view of design - crafting artefacts through a critical engagement with form and material, and foregrounding curiosity on the part of the designer (TEI 2010). Such intangible qualities as meaning, authenticity, commitment, engagement and passion are becoming central to contemporary design, qualities which arguably not only characterise but constitute craft, and which can be found discussed throughout the craft literature.

Coming from Craft to $\mathrm{HCI}$, Interaction Design and tangibles, this is an exciting moment. Craft is no longer being defined simplistically as hand-made goods, nor are assumptions being made about the cultural status of 'the C-word' in relation to Design or to Art (and to be fair, these can sometimes appear to be the only two issues exercising the craft community itself). Instead, intelligent questions and propositions are being put forward, and a hand extended now from $\mathrm{HCI}$ to Craft as a discipline with something important to contribute to emerging creative practices. Given this well articulated interest, I'd like to offer my thoughts on the subject and outline how craft itself is undergoing a significant shift from an activity defined by local praxis, to a form of knowledge and engagement with the world.

\section{I think I know what craft is - why do you have to tell me?}

First of all, it is important to own up to what looks like a serious problem with craft: it doesn't seem to know what it is. You can pick up any piece of the literature, and find a quote to this effect. It is possible to write almost any definitive statement about craft, and for the opposite position to simultaneously hold true:

\footnotetext{
Craft can be a confusing word. When you use it there is a strong possibility that the other person is thinking about something quite different to you. One person imagines handmade one-off pieces while another thinks of stencilled furniture and stamps. And it doesn't get any easier when you get beyond the word craft to a specific discipline such as glass or textiles, as again everyone will imagine something different.
}

Cochrane 2007 
Like design, craft is a value-driven activity and has undergone large ideological shifts since the mid nineteenth century, but in contrast to design, craft has suffered from the serious lack of a coherent historiography. Since the flurry of political theorization at the turn of the nineteenth century with the rise of the Arts and Crafts movement, there has been very little critical discussion in the field. Craft quickly became a byword for the positive values seen to be challenged by industrialization, and as a bastion of the unspoken tacit knowledge being championed by continental philosophy and pedagogy. As late as 1997, craft's 'secret knowledge' was still being jealously guarded from rational analysis and critical discourse, and it wasn't until 2004 that a series of international conferences brought together makers and thinkers to seriously question crafts myths ${ }^{1}$.

The result of this situation has been an oversimplification of the domain's shift from pre-modernism to modernism, placing the traditional in opposition to the new. The consequent need to retell and constantly qualify this history detracts from the important threads that continue to characterise craft, and from the crucial part it may play in its contemporary fluid form.

\section{Something old...}

In the traditional view of craft, the object is predominantly hand made, and those technologies that are in use have been an integral part of specific techniques for hundreds of years: witness the jeweller's saw frame and workbench, found in illustrations of 16th Century workshops and earlier. A romanticised vernacular vision, this version of craft is often portrayed as somehow closer to or representative of some utopian ideal. Pugin, Ruskin, and Morris and their followers explicitly combined lifestyle with aesthetic choices that championed the mediaeval as an ideal. The Arts and Crafts movement had an unprecedented global impact in its own time, but has also handed down a legacy that has proven difficult to escape. The complexity of the movement's history and personalities ${ }^{2}$ are often lost in a kind of short hand for its most renowned tenets: that craft sits in opposition to industrialization; that craft centers on the experience of hand making; that all beauty derives from nature; and that the worker must be free for the work to be good.

Authenticity for the Arts and Crafts had a distinctly socialist political flavour as well as an ideological approach to form. Its roots lay in a concern for a respectful relationship between design, society and nature, which appeared to be in danger as the industrial revolution progressed. Conditions of manufacture, formal attributes, and the way designs could inform engaged ownership ${ }^{3}$ were all

\footnotetext{
${ }^{1}$ Craft in the Twenty First Century (2003), Edinburgh, UK; Challenging Craft (2004), Aberdeen, UK; New Craft, Future Voices 2007), Dundee, UK; NeoCraft (), Canada; Crafticulation (2008), Helsinki, Finland

${ }^{2}$ Rosalind Blakesley provides an excellent overview (2006).

${ }^{3}$ A clear example would be the Shaker style furniture of the American Arts \& Crafts movement which removed ornament and promoted an austere form of honest existence
} 
important in the creation of goodness and beauty, which were in fact synonymous to the movement's leaders. Integrity, holism and authenticity were expressed in a number of ways through form: materials were respected for their own characteristics, to be understood through hands on engagement; the function of things was not to be disguised; and any ornament should arise from structural elements rather than be applied arbitrarily. Beauty could only be present in an object that had been made by a contented worker, and was also seen as arising from its usefulness once in existence. In this way, we might say that communities of practice and social conditions were important to the Arts \& Crafts not only in the manufacture of goods, but in the manner of their consumption.

There have been problems with the 'revolution in manufacture' proposed by the Arts and Crafts however. Despite its best intentions, it has been criticized for fetishising unthinking labour, and over time its signifier, the mark of the maker, has been seriously challenged by the ability of the machine to mimic craft's randomness. What was once a reliable expression of a particular culturally charged process is no longer necessarily connected with it in any way.

\section{Something new...}

The beliefs of the Arts and Crafts movement continued to play out through other movements such as the Jugendstil and the Bauhaus as the economic and political forces of the twentieth century were added to the industrialized manufacturing landscape, until New Craft, as distinct from the traditional model, emerged as a paradigmatic shift in Western culture in the 1960's. 'Studio craft' assiduously maintained that craft was an artistic practice at least as 'fine' others, and argued vehemently for its equal status. This status was, and continues to be, engineered through a number of key strategies, including framing mechanisms such as critical discourse and display cultures, a rejection of functionality and the domestic, or a rejection of material itself. Expressions of individuality took the place of craft's traditional user-centredness and work was produced in studios by individuals, who made the explicit decision to be in control of both the conception and realisation of their work (thereby implying new modernist models of authority and ownership). This individualism was also extended to the experience and consumption of craft objects, as they became exhibited in rarified gallery environments, surrounded by white space, and bought as the ultimate statement of individual connoisseurship and identity. Craft emulated fine art's claims to authenticity through its use of these strategies and valorized the ideals of the Enlightenment: the purity of the conceptual untainted by worldly bodies or material, and the artlessness of spontaneous expression 4 .

It has taken some time for Craft to reflect more deeply upon its own rather messier and contingent forms of authenticity, rather than merely defining itself in relation to art, but contemporary writing in the field is attempting to learn from both the traditional and the modernist views, and reflects in many ways shifts in how philosophy itself is developing a new and fluid form of authenticity.

\footnotetext{
${ }^{4}$ for example, in the action art approach taken by influential ceramicist Peter Voulkos
} 


\section{Fluidity}

The problem for us now is that neither of these dominant oppositional accounts of craft is able to tell the full story any more. The more we attempt to define craft through these polarized frames, the more it slips away from us. To help, we can think of craft as something that is fluid: as a process, as an object, and as a cultural frame.

Craft has never been simply functional, even at its most traditional, nor will it ever be entirely autonomous, even at its most modern. While it is an object focused discipline, the craft object is never an end in itself - craft objects are also means to ends. And even at their most rarefied, they retain vestiges of functionality, domesticity and flow. They remain craft as long as there is that embodiment of humanity resulting from process, or evident in references to potential or historical functionality. Similarly, the functional craft object is never entirely transparent, nor does it intend to be. It is always available for contemplation. The crafted bowl is as available to the mantelpiece as to the kitchen cupboard, as appropriate in the gallery as in the ethnographic museum. In use it passes through moments of presence and disappearance, and also, importantly, has the ability to create an experiential space that blends these in a special kind of awareness. To take an example, Chris Knight's silver shot glasses fulfill the functional requirements for drinking tequila - their scale and form is right according to our experience - but the act of holding these spiky tumblers draws immediate attention to the danger inherent in the activity they are designed for.

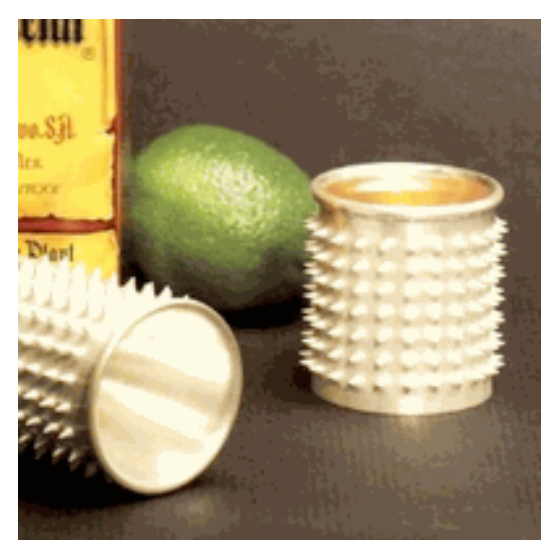

awareness in action

Chris Knight: silver shot glasses

Craft objects have always had the capacity to segue between transparency and reflection, that most pressing issue for Tangible Interaction Design. They have always occupied, even constituted, a unique place between art and life, available for the aesthetic experience, yet part of the ongoing flow of pragmatic action. They are rhythmical in their cultural configuration as well as in their internal formal organisation. They retain elements of the traditional model and of the modern, combining tacit and narrative experience in a smeared simultaneity. 
Contemporary craft as it is engaged with the world around it, social, formal and political, is thus dynamically configured as its traditional romantic self, in its modern guise as art, and as experimental intervention, in a situation where none of these takes precedence.

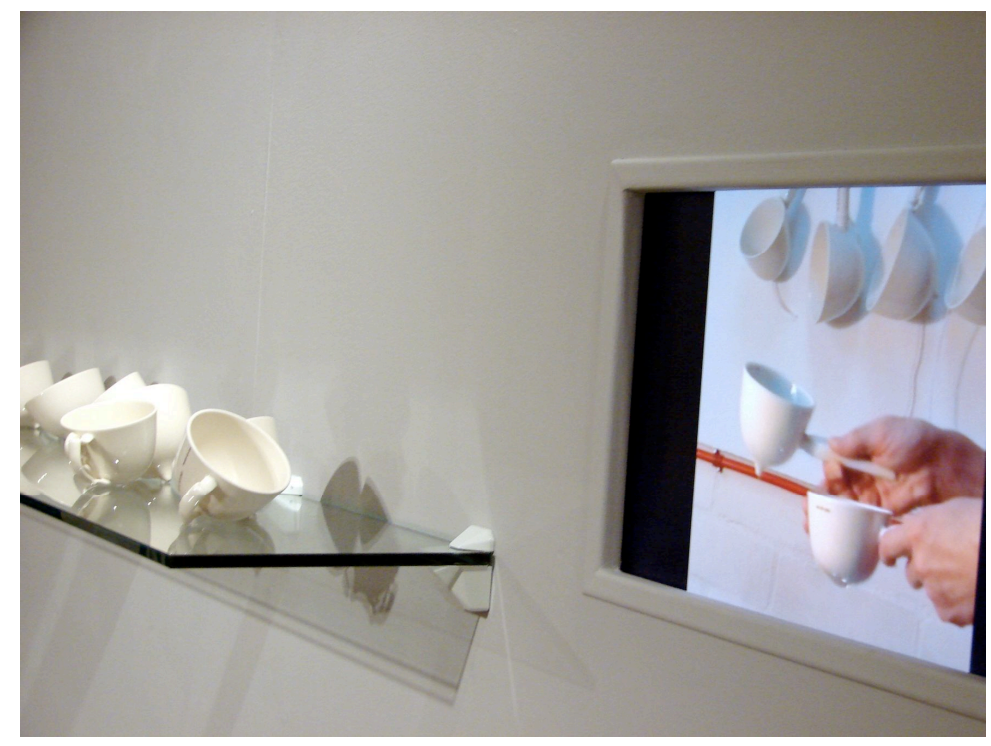

Adriana lonascu's ceramic installation is full of beautifully made vessels and cups with no determined function. They invite play and the co-creation of meaning rather than promoting a fixed intent.

lonascu (2007)

This model of craft is exciting because it echoes so clearly the terminology and characteristics of authenticity and authentic experience. Philosophy is arguing the case for hybridity in authenticity, just as we are encountering it in the cultural sphere, and is in the process of constructing new understandings of the relationships between the sublime and the mundane (Guignon 2004). Both Craft and Philosophy can be seen to find authenticity in a dismantling of old dichotomies - useful/aesthetic, reflective/transparent, flow/event (Kettley 2005). Craft objects provide contexts for moving in and out of experience and for a heightened awareness of somatic experience, and their contemporary fluidity encourages openness to experience and engenders processes of meaning making rather than presenting predetermined significations.

\section{Crafting tangible interfaces}

This contemporary form of Craft offers a promising model for the development of tangible computational products that seek to be metaphorically meaningful as well as useful, and as one of the earliest interactive art forms, offers us a unique opportunity to shape our new technologies. It allows us to rethink the nature of material itself and to explore the values we wish to embed in our emerging communities of practice. 


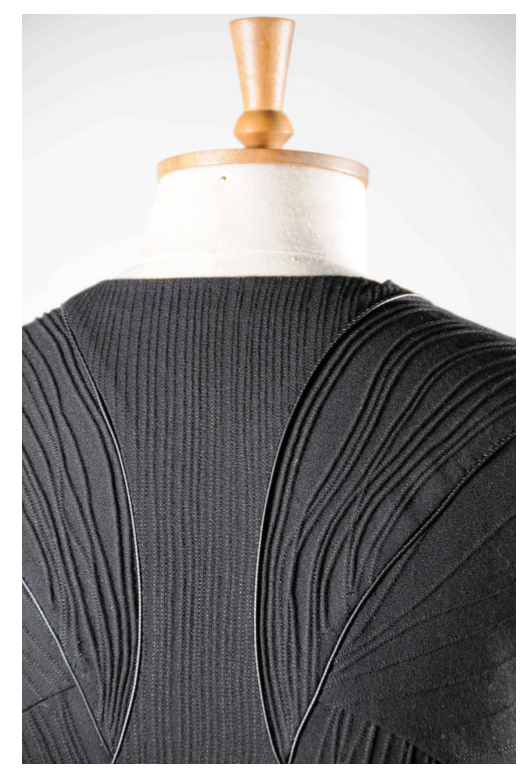

Aeolia: stretch sensor garment, 2009

Sarah Kettley (project lead)

embroidery by Tina Downes

garment fitting by Karen Harrigan

\section{References}

Blakesley, R. (2006). The Arts and Crafts Movement. Phaidon Press.

Cochrane, G. (2007). What is Craft? craftscotland.

http://www.craftscotland.org/whatiscraft.html. Retrieved 12/06/07.

Guignon, C. (2004). On Being Authentic. London: Routledge.

Ionascu, A. (2007). The Anatomy and Aesthetics of use. In G. Folett, S. Moir \& L. Valentine (Eds.). Future Voices: Celebrating Dversity. Exhibition Proceedings New Craft - Future Voices. Duncan of Jordnstone College of Art and Design. July 2007. pp.74-77.

Kettley, S. (2005). Crafts Praxis as a Design Resource. In P. Rodgers, L. Brodhurst, \& D. Hepburn (Eds.). (2005). Crossing Design Boundaries, pp.545-549.

London: Taylor \& Francis Group.

TEI (2010). Proceedings of the $4^{\text {th }}$ International Conference on Tangible, Embedded \& Embodied Interfaces, Media Lab, MIT, Cambridge, MA.

\section{About the author}

Sarah Kettley is a maker and writer. She trained as a jeweller at Glasgow School of Art before becoming interested in Wearable Computing. She completed a PhD in Craft as a design methodology for Wearables at Edinburgh Napier University's Center for Interaction Design in 2007, and is now a senior lecturer in the product 
design subject area at Nottingham Trent University. Her digital jewellery can be seen this summer at the Bonhoga Gallery, Shetland, and recent collaborative stretch sensing textiles can be seen at Create 2010, Edinburgh, and at the Festival Of Craft, Dundee, all between May and July 2010.

sarah.kettley@ntu.ac.uk

www.sarahkettleydesign.co.uk 